\title{
Effects of Pre-annealing Atmosphere on Microstructure and Photocatalytic Activities of Fe-doped Titania Nanotubes
}

\author{
Shi Zhiming, Ma Rui, Zhang Xiyu, Wang Lina, Wang Xiaohuan \\ Inner Mongolia University of Technology, Hohhot 010051, China
}

\begin{abstract}
The nanotubes with an anatase structure were hydrothermally synthesized using the Fe-doped anatase nanopowder precursors that were annealed in air and reductive atmospheres. The microstructure and physicochemical properties of the nanotubes were comparably investigated. Results show that the reductive pre-annealing yields more surface-chemisorbed oxygen by introducing lower valance $\mathrm{Fe}^{2+}$ and $\mathrm{Ti}^{3+}$ ions. The specific surface area, methylene blue adsorption and photoabsorption threshold of the nanotubes are greatly enhanced by the reductive annealing when comparing with annealing in air. 1 mol\% Fe doping and reductive annealing yield the highest adsorption, photocatalytic efficiency and durability for degradation of MB solution; extreme Fe doping decreases the photocatalytic efficiency. The Fe content of the nanotubes is decreased by the hydrothermal synthesis, especially in the case of annealing in air. Moreover, the action mechanism of the Fe doping and reductive annealing was discussed.
\end{abstract}

Key words: titania; nanotubes; reductive annealing; doping; photocatalysts; crystal defects

Nanostructured titania has been widely used in photocatalytic degradation of organic pollutants. The preparation, microstructure and photocatalytic behavior of titania nanostructures, especially the one-dimensional nanotubes, have been paid great attention to due to their superior physicochemical properties, such as large disparity, high surface activity and the fast charge transition when compared with titania nanoparticles. Hydrothermal method is generally adopted to synthesize titania nanotubes that have a diameter of $10 \mathrm{~nm}$ approximately and exhibit an anatase phase or anatase+rutile biphase ${ }^{[1-4]}$. Photocatalytic activity follows the order of nanotubes > nanorods > nanobelts > P25 nanoparticles ${ }^{[5]}$. However, the titania crystals have restricted photoadsorption ability because of their larger band gap (3.2 eV for anatase and $3.0 \mathrm{eV}$ for rutile). Ion-doping is frequently adopted to decrease the band-gap by generating donors or acceptors in the band that favor to separate photo-generated electrons and holes and inhibit their rapid recombination ${ }^{[6-9]}$, and Fe doping is the most attractive among them because it produces great changes in microstructure and physicochemical behaviors of the nanostructured titania ${ }^{[10-12]}$. However, the optimized Fe content varies with the applied preparation method, morphology and phase composition of titania structures and the sacrificial organics. For example, by doping with 0.5 mol\% $\mathrm{Fe}$, the $\mathrm{TiO}_{2}$ nanorods possessed a photocatalytic activity more than two-times of the Degussa P25 ${ }^{[13]}$, the $\mathrm{TiO}_{2}$ microspheres doped with $0.5 \mathrm{~mol} \% \mathrm{Fe}$ had a high surface area, well-crystallized anatase phase and the best photocatalytic degradation of phenol ${ }^{[14]}$. $0.5 \mathrm{wt} \% \mathrm{Fe}$ doped $\mathrm{TiO}_{2}$ hollow nanospheres show the highest photocatalytic activity that exceeds that of the undoped $\mathrm{TiO}_{2}$ for degradations of 2, 4, 6-trichlorophenol and red X-3B dye respectively ${ }^{[15,16]}$. 1.0 mol\% $\mathrm{Fe}$-doped dual-phase $\mathrm{TiO}_{2}$ containing $20.64 \mathrm{wt} \%$ of rutile phase induced a red shift of absorption edge and yielded the best degradation efficiency for methyl orange ${ }^{[17]}$. $1.5 \mathrm{~mol} \% \mathrm{Fe}$ doping also produced the best photocatalytic activity ${ }^{[18]}$. Moreover, Fe doping

Received date: November 28,2016

Foundation item: National Natural Science Foundation of China (51262021)

Corresponding author: Shi Zhiming, Ph. D., Professor, School of Materials Science and Engineering, Inner Mongolia University of Technology, Hohhot 010051, P. R. China, Tel: 0086-471-6575752, E-mail: shizm@imut.edu.cn 
increased the surface area and pore volume of sol-gel derived titania nanopowders; a doping with $3.0 \mathrm{~mol} \% \mathrm{Fe}$ exhibited a significantly high surface area and pore volume $^{[19]}$. On the contrary, the surface area of titania nanotubes was decreased while the adsorption amount for arsenic was increased by $\mathrm{Fe}$-doping ${ }^{[20]}$, indicating a significant change in surface activity of the nanotubes. A substantial photodegradation efficiency of the titania thin film can also be achieved at very high doping levels, such as $20 \mathrm{~mol} \% \mathrm{Fe}^{3+[21]}$. However, the studies on $\mathrm{Fe}$-doped titania nanotubes have been paid less attention to.

Moreover, self-doping is a novel method that introduces low-valance $\mathrm{Ti}^{3+}$ species and oxygen vacancies in bulk and surface of the $\mathrm{TiO}_{2}$ structures. They decreased the band gap of the crystals, maximized the photoabsorption activity and improved the photocatalytic behavior ${ }^{[22-25]}$. Another alternative approach to promote photoabsorption and photocatalytic reactions is generation of the disorders in surface of the $\mathrm{TiO}_{2}$ nanocrystals by a hydrogenation treatment, which created much narrow band gap, provided trapping sites for photogenerated carriers, promoted electron transfer and prevented their rapid recombination by yielding mid-gap (band tail) states ${ }^{[26]}$. The $\mathrm{Ti}^{3+}$ sites and oxygen vacancies can be produced by high-temperature annealing, oxygen-lack annealing and the substitution of lower-valance ions such as $\mathrm{Fe}^{3+} / \mathrm{Fe}^{2+}$ for $\mathrm{Ti}^{4+}{ }^{[27-29]}$. For example, $15 \mathrm{~mol} \%$ of Fe ions can be completely dissolved into titania lattices by annealing in a reductive atmosphere, which resulted in presence of the lower-valance $\mathrm{Fe}^{2+}$ and $\mathrm{Ti}^{3+}$ ions and much more oxygen vacancies ${ }^{[30]}$. However, the crystals containing $\mathrm{Ti}^{3+}$ ions and oxygen vacancies may be unstable, especially in an oxidation environment ${ }^{[31,32]}$. Therefore, synthesis of the stable $\mathrm{TiO}_{2}$ photocatalysts with the self-dopants is significant in practice.

Based on advantages of the one-dimension, Fe-doping and self-doping, the Fe-doped titania nanotubes with an anatase phase were prepared using a reductive annealing of the precursory anatase nanopowders and a hydrothermal synthesis; the characters of microstructure and physicochemical behaviors of the nanotubes were comparatively investigated to try to find the coupling effect of Fe-doping and the reduction treatment on them.

\section{Experiment}

Analytical reagents of tetrabutyl titanate $\left(\mathrm{Ti}\left(\mathrm{OC}_{4} \mathrm{H}_{9}\right)_{4}\right)$, ferric nitrate $\left(\mathrm{Fe}\left(\left(\mathrm{NO}_{3}\right)_{3} \cdot 9 \mathrm{H}_{2} \mathrm{O}\right)\right.$ and absolute alcohol $\left(\mathrm{C}_{2} \mathrm{H}_{5} \mathrm{OH}\right)$ were used as starting materials. $100 \mathrm{~mL}$ of tetrabutyl titanate was injected into $400 \mathrm{~mL}$ of absolute alcohol to form a base solution under stirring for $30 \mathrm{~min}$, which was then divided into four equal parts. Different amounts of ferrous nitrate were individually dissolved into the solutions to form Fe-doped titania sols with different $\mathrm{Fe} / \mathrm{Ti}$ ratios $(\mathrm{mol} \%)(0.0,1.0,2.0$ and 3.0). The sols were vigorously stirred for $30 \mathrm{~min}$ and aged for $24 \mathrm{~h}$. By heating the aged sols in stirring to $60{ }^{\circ} \mathrm{C}$ and drying at $100{ }^{\circ} \mathrm{C}$ for 24 $\mathrm{h}$, the titania gels were obtained. The dried gels were annealed at $400{ }^{\circ} \mathrm{C}$ for $2 \mathrm{~h}$ in air atmosphere in a tube-type furnace and cooled to room temperature. To conduct a reductive annealing, $\mathrm{CO}-\mathrm{Ar}$ hybrid gas was introduced to the furnace with a volume ratio of 1: 2 and a flux of 150 $\mathrm{mL} / \mathrm{min}$. Before the test started, the furnace was degased by flowing pure Ar for $10 \mathrm{~min}$. These conditions employed was due to that an anatase phase with good crystallinity and small crystals was formed under these conditions ${ }^{[33]}$. The annealed products were ground and screened into powders with a granularity of 74 63 $\mu \mathrm{m}$ (ASTM E11-58T).

The anatase powders $(0.3 \mathrm{~g})$ were placed into a stainless steel reaction kettle filled with a $\mathrm{NaOH}$ solution $(10 \mathrm{~mol} / \mathrm{L})$ to $80 \%$ of the total volume. The autoclave was heated to 120 ${ }^{\circ} \mathrm{C}$ and kept for $16 \mathrm{~h}$ followed by cooling to room temperature. The obtained samples were alternatively washed in stirring with dilute HCI solution and deionized water until they were neutral. The washed samples were dried at $90{ }^{\circ} \mathrm{C}$ for $12 \mathrm{~h}$ to obtain the nanotubes.

The Fe doping, reductive annealing and hydrothermal reaction resulted in changes in color of the products. When annealed in air atmosphere, the powders presented yellowish (undoped), yellow and deep yellow with an increase of $\mathrm{Fe}$ content due to the presence of $\mathrm{Ti}^{4+}$ and $\mathrm{Fe}^{3+}$ ions; when annealed in reduction atmosphere, the undoped powders presented gray color and the $\mathrm{Fe}$-doped powders presented black color, due to the low-valance $\mathrm{Ti}^{3+}$ and $\mathrm{Fe}^{2+}$ ions and the $\mathrm{O}^{2-}$ vacancies ${ }^{[23,29]}$. With the hydrothermal reaction, annealing in air made all of the nanotubes present offwhite color, which may be due to titanate inclusions remaining; the reductive annealing made the nanotubes present deep gray color, which indicates that the low-valance $\mathrm{Ti}^{3+}$ and $\mathrm{Fe}^{2+}$ ions still existed in the nanotubes even though they underwent a long-term of hydrothermal treatment and a repeated washing in the acid solution.

$0.15 \mathrm{~g}$ of the nanotubes were placed in a methylene blue (MB, $\mathrm{C}_{16} \mathrm{H}_{18} \mathrm{ClN}_{3} \mathrm{~S}_{2} \cdot 3 \mathrm{H}_{2} \mathrm{O}$ ) solution $(3 \mathrm{mg} / 150 \mathrm{~mL}$ ) with stirring. After a dark treatment of $30 \mathrm{~min}$, the concentrations of the solutions were inspected as references to determine degradation ratio of the $\mathrm{MB}$ solutions in upcoming photocatalytic reaction. The dark-treated solutions were irradiated for $60 \mathrm{~min}$ by an ultraviolet lamp with a weaker power $(50 \mathrm{~W}, 356 \mathrm{~nm})$. The absorbance of the solutions cleaned by centrifugal separation was inspected every $10 \mathrm{~min}$ using UV-Vis spectrophotometry (UV-3101PC). The degradation ratio can be obtained by following calculation formulae $^{[34]}$.

$$
\begin{aligned}
& A=0.019+0.197 C \\
& \eta=C_{\mathrm{t}} / C_{0}
\end{aligned}
$$

where, $A$ is the absorbance, $C$ is the concentration of MB in solution, $C_{0}$ is the original concentration (reference) and $C_{\mathrm{t}}$ is 
the concentration in time; $\eta$ is the degradation ratio.

To examine degradation durability of the nanotubes, a recycle test were conducted. The concentration of the exhausted solutions was repeatedly increased to the starting concentration $(3 \mathrm{mg} / 150 \mathrm{~mL})$ and irradiated for $60 \mathrm{~min}$ to inspect the changes in absorbance.

The phase composition was analyzed using an $\mathrm{X}$-ray diffractometer (XRD) (D/MAX-2500/PC, Rigaku) with $\mathrm{Cu} \mathrm{K \alpha}$ radiation at $40 \mathrm{kV} / 40 \mathrm{~mA}$ and a scanning speed of $1 \% \mathrm{~min}$. The morphology of the nanotubes was observed using a transmission electron microscope (TEM) (FEI Tecnai F20). The valance of $\mathrm{Fe}$ and $\mathrm{Ti}$ ions was determined by an X-ray photoelectron spectrometer (XPS) (Kratos-Amicus, Shimadzu), using $\mathrm{Mg} \mathrm{K} \alpha$ as the radial source. The binding energy was corrected by the $\mathrm{C} 1 \mathrm{~s}$ level. The specific surface area of the nanotubes was inspected using the Brauner-Emmett-Teller analysis (BET, QuadraSorb Station 1). The photoabsorption was inspected using the UV-Vis spectrophotometry. The Fe and $\mathrm{Na}$ contents in the nanotube samples were determined using an inductively coupled plasma-atomic emission spectrometer (ICP-AES, OPTIMA 7000 DV).

\section{Results}

\subsection{Phase composition and morphology of the nanotubes}

All of the nanotubes are mainly composed of anatase $\mathrm{TiO}_{2}$ (PDF\#21-12723) as shown in Fig.1; very little $\mathrm{Na}_{2} \mathrm{Ti}_{6} \mathrm{O}_{13}$ (PDF\#37-0951) phases are present in undoped and $1 \mathrm{~mol} \% \mathrm{Fe}$-doped samples. Ferro oxides are not found in the Fe-doped samples. It is well known that the precursor titania nanocrystals are first transformed into lamellar structure in an alkali solution during hydrothermal reaction and the titanites of $\mathrm{Na}_{2} \mathrm{Ti}_{6} \mathrm{O}_{13}$ and/or $\mathrm{Na}_{2} \mathrm{Ti}_{3} \mathrm{O}_{7}$ as byproducts are companied ${ }^{[35-37]}$. With an increase of reaction time, the lamellar structures are curled into short tubular structures and further grow into long nanotubes by wrapping a (101) or (100) plane along the [010], [100] or [110] direction ${ }^{[5,38-40]}$. Most of the titanites can be also transformed into $\mathrm{H}$-titanites and ultimate $\mathrm{TiO}_{2}$ nanotubes due to an exchange of $\mathrm{H}^{+}$with $\mathrm{Na}^{+}$by repeated washing in an acidic solution and heating at relatively low temperatures. However, very little $\mathrm{Na}_{2} \mathrm{Ti}_{6} \mathrm{O}_{13}$ titanites still remain in the products (Fig.1). Fe doping and the reduction treatment decreases the amounts of the titanites, which is confirmed by trace of $\mathrm{Na}$ in the ICP-AES results (Table 1). In addition, the $\mathrm{Fe}$ contents of the nanotubes are found to be decreased, especially in the case of annealing in air when comparing with the as-received batches. This is ascribed to the limited solubility of $\mathrm{Fe}^{3+}$ in anatase lattice, lamellar titanites and the tubular $\mathrm{H}_{2} \mathrm{Ti}_{3} \mathrm{O}_{7}$; the extra $\mathrm{Fe}^{3+}$ ions in form of $\mathrm{Fe}_{2} \mathrm{O}_{3}$ in their surface are removed in $\mathrm{NaOH}$ and $\mathrm{HCl}$ solutions ${ }^{[41,42]}$. On contrary, the reductive annealing makes the $\mathrm{Fe}$ ions completely dissolve into titania lattice by

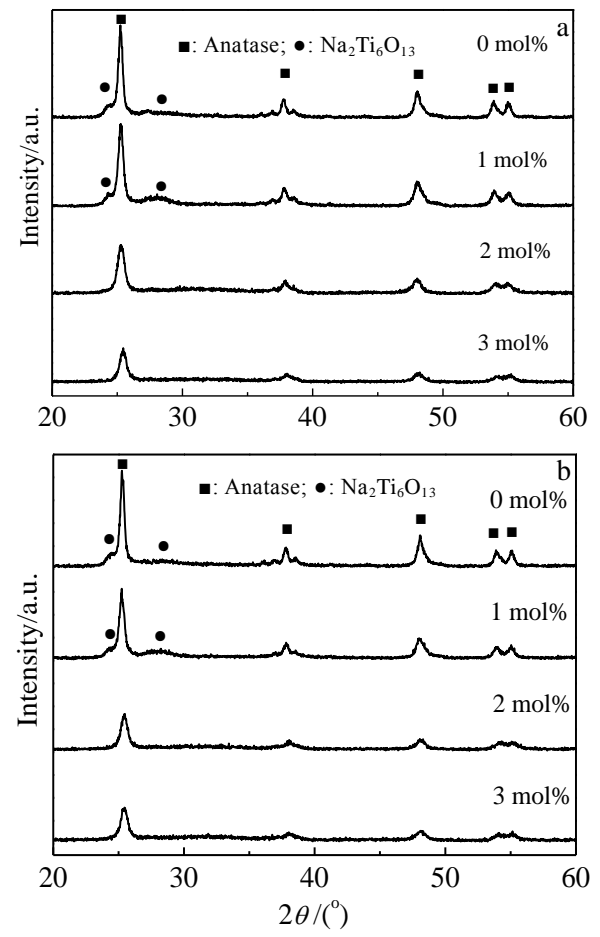

Fig.1 XRD patterns of Fe-doped titania nanotubes in different pre-annealing atmospheres: (a) air and (b) reduction

Table 1 Contents of $\mathrm{Fe}$ and $\mathrm{Na}$ in the $\mathrm{Fe}$-doped nanotubes $(\mathrm{mol} \%)$

\begin{tabular}{cccc}
\hline $\begin{array}{c}\text { Nominal content of } \\
\mathrm{Fe}\end{array}$ & $\begin{array}{c}\text { Reductive } \\
\text { annealing }\end{array}$ & $\mathrm{Fe}$ & $\mathrm{Na}$ \\
\hline \multirow{2}{*}{0.0} & No & - & 0.23 \\
& Yes & - & 0.16 \\
\hline \multirow{2}{*}{1.0} & No & 0.89 & 0.19 \\
& Yes & 0.96 & 0.16 \\
\hline \multirow{2}{*}{2.0} & No & 1.37 & 0.13 \\
& Yes & 1.82 & 0.10 \\
\hline \multirow{2}{*}{3.0} & No & 2.16 & 0.14 \\
& Yes & 2.65 & 0.12 \\
\hline
\end{tabular}

substitutions of $\mathrm{Fe}^{2+}$ (LS) for $\mathrm{Ti}^{4+}$ and the $\mathrm{Fe}^{2+}$ (LS) and $\mathrm{Fe}^{3+}$ (HS) for $\mathrm{Ti}^{3+}{ }^{[30]}$; only the small amounts of $\mathrm{Fe}^{3+}$ ions in their surface are removed by washing in $\mathrm{NaOH}$ immersion and $\mathrm{HCl}$.

The nanotubes are $10 \mathrm{~nm}$ in diameter and more than 50 $\mathrm{nm}$ in length approximately as shown in Fig.2; Fe doping and the reductive annealing have less influence on size and morphology of the nanotubes, which is due to that the lamellar and tubular structures and the anatase lattice are not greatly influenced by the treatments. This proves that the perfect nanotubes with good crystallinity and high-content of anatase phase are obtained. 


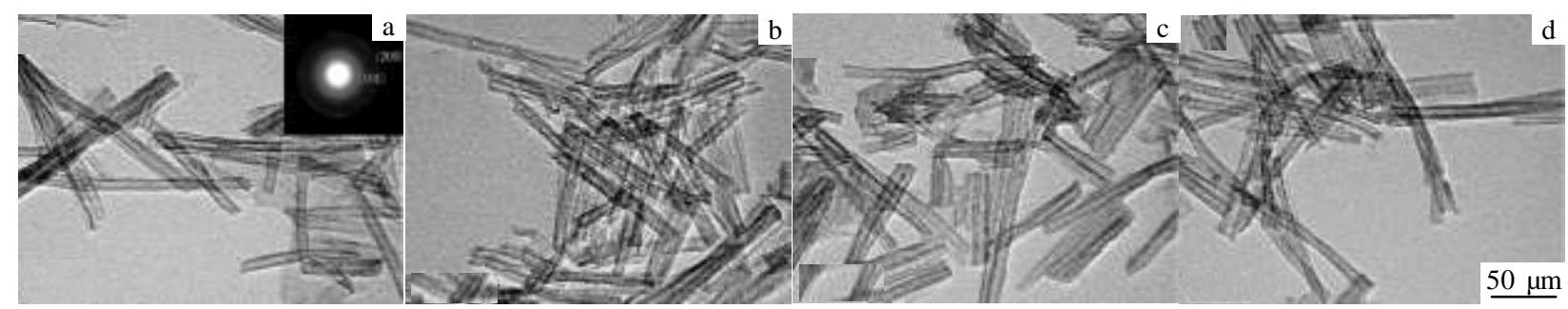

Fig.2 TEM morphologies of the nanotubes: (a) undoping and annealing in air; (b) undoping and reductive annealing; (c) 1 mol\% Fe-doping and annealing in air; (d) 1 mol\% Fe-doping and redtive annealing

The BET test shows an increased specific surface area of the nanotubes, slightly by $\mathrm{Fe}$ doping and greatly by reductive annealing (Fig.3). 2 mol\% Fe doping yields little higher specific surface area $\left(246.6 \mathrm{~m}^{2} / \mathrm{g}\right)$ in the case of annealing in air; while the reductive annealing largely enhances the specific surface area and $1 \mathrm{~mol} \%$ Fe doping yields the highest value of $268.4 \mathrm{~m}^{2} / \mathrm{g}$.

\subsection{Ionic valance and oxygen vacancy}

The elements of the nanotube samples are shown in Fig.4 by XPS measurement. From the separated patterns of Ti $2 p$, Fe $2 \mathrm{p}$ and $\mathrm{O} 1 \mathrm{~s}$ peaks appear for the typical undoped and 3 mol\% Fe-doped nanotubes (Fig.5). It can be noticed that only high-valance $\mathrm{Ti}^{4+}$ and $\mathrm{Fe}^{3+}$ ions exist in the samples annealed in air (Fig.5a and Fig.5c); while the reductive annealing introduces low-valance $\mathrm{Ti}^{3+}$ and $\mathrm{Fe}^{2+}$ ions (Fig.5b and Fig.5d). The $\mathrm{O} 1 \mathrm{~s}$ peak is resolved into two individual peaks, which respectively ascribe to surface-chemisorbed oxygen $\left(\mathrm{O}_{\alpha}\right)$ and lattice oxygen $\left(\mathrm{O}_{\beta}\right)$ (Fig.5e and Fig.5f). Table 2 shows the relative percentage of the ions for themselves. The Fe-doping and reductive annealing resulted in an increase in surface-chemisorbed oxygen and a decrease in lattice oxygen; the reductive annealing has a stronger effect than Fe-doping. On the other hand, the decrease in lattice oxygen indicates an increase in oxygen vacancy concentration. The variations in ionic valance, relative content, oxygen form and oxygen vacancy concentration are responsible of photoabsorption and photocatalytic ability.

\subsection{Photoabsorption, MB adsorption and photocatalytic behaviors of the nanotubes vacancy}

\subsubsection{Photoabsorption}

The wavelength of photoabsorption edge is increased (red shift) by Fe-doping (Fig.6a) and greatly by reduction treatment (Fig.6b). When annealed in air, the wavelength is $385 \mathrm{~nm}$ for undoped sample and 414 439 $\mathrm{nm}$ for $1 \mathrm{~mol} \% \sim 3 \mathrm{~mol} \%$ Fe doped samples; with the reductive treatment, the wavelength arrives at 541 and $592 \mathrm{~nm}$ (maximum) for undoped and $1 \mathrm{~mol} \% \mathrm{Fe}$ doped samples, respectively. In addition, the curves are shifted up by the Fe doping and reduction treatment, indicating a simultaneous

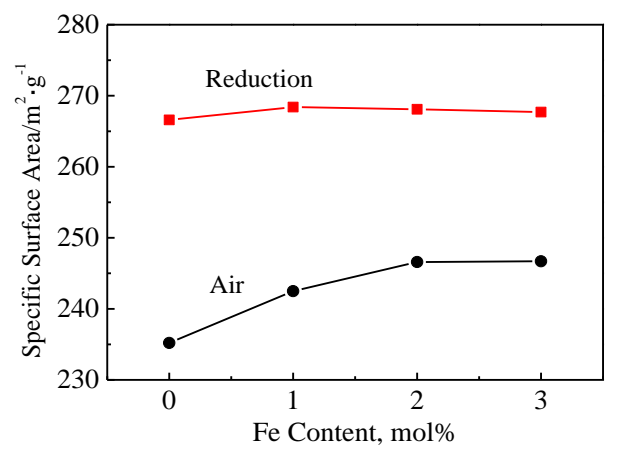

Fig.3 Specific surface area of Fe-doped nanotubes in different pre-annealing atmospheres

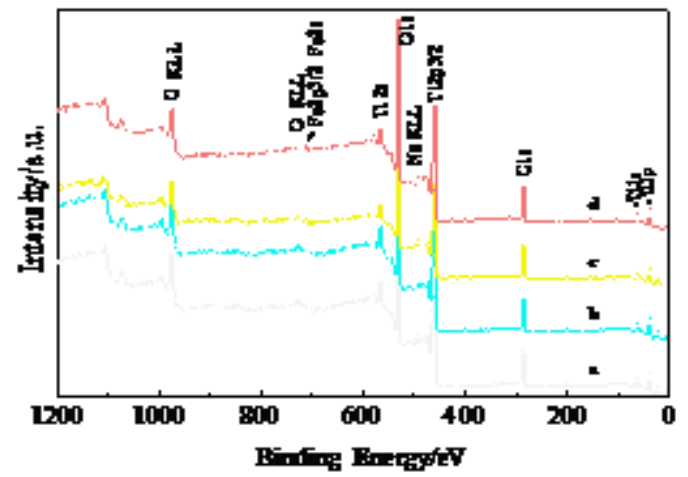

Fig.4 XPS spectra of the nanotube sample: (a)undoping and anneaing in air; (b)undoping and reductive annealing; (c) 3 mol\% Fe-doping and annealing in air; (d)3 mol\% Fe-doping and reductive annealing

improvement in photoabsorption flux of the titania nanotubes.

2.3.2 MB adsorption

Fig.7 shows the variations of $\mathrm{MB}$ concentration in solutions in $30 \mathrm{~min}$ of dark treatment; the adsorption ratio of the nanotube samples can be obtained from these results. When annealed in air, the Fe doping yields about $70 \%$ of 

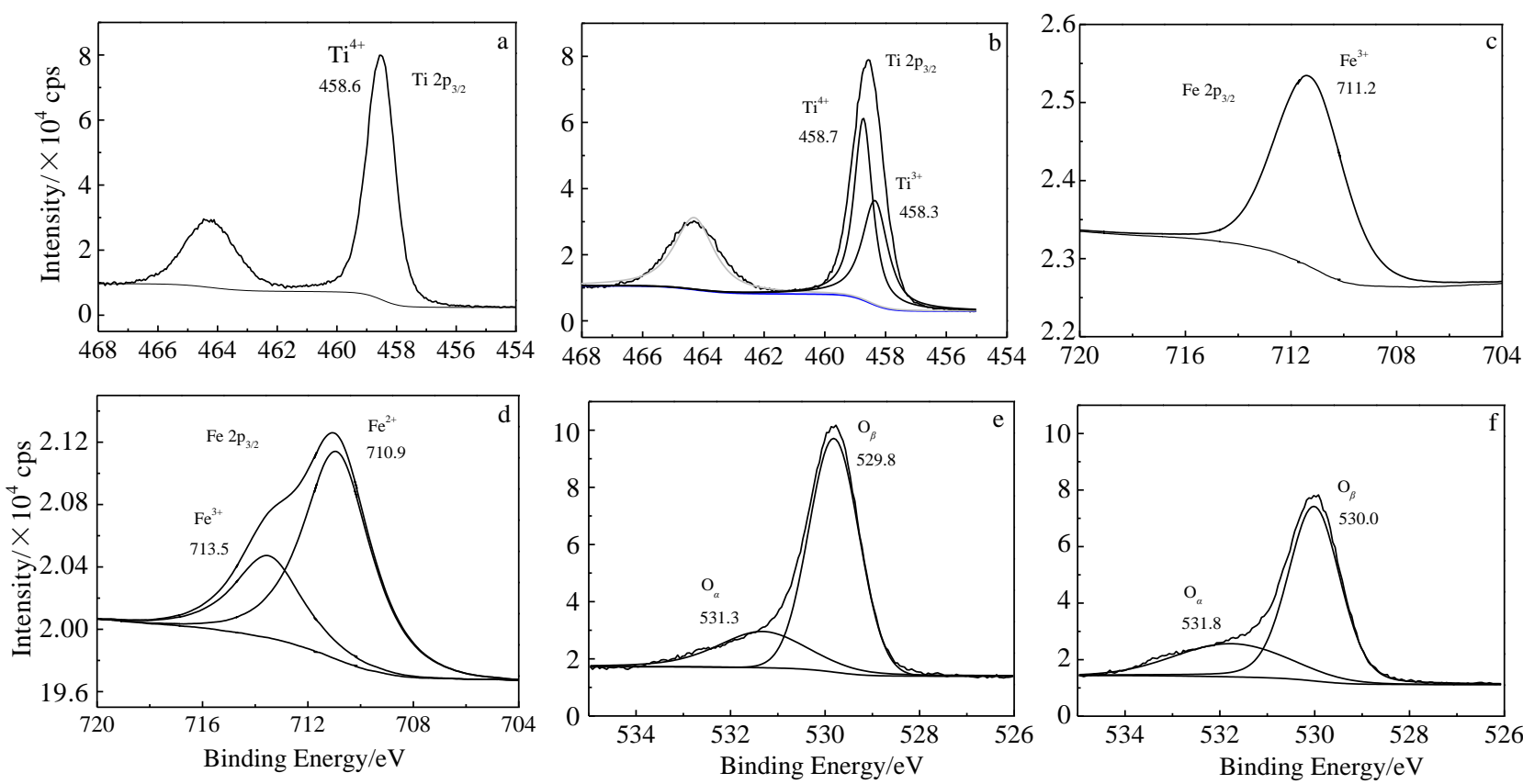

Fig.5 XPS spectra of Ti 2p peaks annealing in air (a) and reductive annealing (b); Fe 2p peaks annealing in air (c); reductive annealing (d); $\mathrm{O}$ 1s peaks annealing in air (e); reductive annealing (f) for the 3 mol\% Fe-doped nanotube sample

Table 2 Relative contents of ions in the Fe-doped noontide samples

\begin{tabular}{cccccccc}
\hline \multirow{2}{*}{$\begin{array}{c}\text { Fe dopant/ } \\
\text { mol\% }\end{array}$} & $\begin{array}{c}\text { Reductive } \\
\text { annealing }\end{array}$ & \multicolumn{5}{c}{ Relative content/\% } \\
\cline { 3 - 7 } & $\mathrm{Ti}^{4+}$ & $\mathrm{Ti}^{3+}$ & $\mathrm{Fe}^{3+}$ & $\mathrm{Fe}^{2+}$ & $\mathrm{O}_{\alpha}{ }^{2-}$ & $\mathrm{O}_{\beta}{ }^{2-}$ \\
\hline \multirow{2}{*}{0} & No & 100 & 0 & - & - & 6.9 & 93.1 \\
& Yes & 87.6 & 12.4 & - & - & 19.3 & 80.7 \\
\hline \multirow{2}{*}{3} & No & 100 & 0 & 100 & 0 & 15.5 & 84.5 \\
& Yes & 55.7 & 44.3 & 33.7 & 66.3 & 26.7 & 73.3 \\
\hline
\end{tabular}

adsorption of $\mathrm{MB}$, which is higher than that of the undoped case (nearly 60\%) (Fig.7a). 1 mol\% Fe doping and the reductive treatment yields the highest adsorption of nearly 90\% (Fig.7b). The adsorption behavior can also be confirmed by the SEM results as shown in Fig.8. The surface of the nanotubes is completely covered by the $\mathrm{MB}$ in the case of 1 mol\% Fe doping and reductive treatment (Fig.8d), indicating enhancement of the adsorption ability.

2.3.3 Photocatalytic behaviors of the nanotubes

The degradation efficiency is enhanced by Fe-doping and the reduction treatment (Fig.9). When annealed in air, $1 \mathrm{~mol} \% \sim 2 \mathrm{~mol} \% \mathrm{Fe}$ doping yields about $85 \%$ of degradation, which is higher than that of the undoped case (nearly $70 \%$ ); $1 \mathrm{~mol} \% \mathrm{Fe}$ doping and the reduction treatment yields the highest degradation efficiency of over $95 \%$ and the fastest degradation rate in such a weak UV irradiation $(50 \mathrm{~W})$. Fig.10 shows the durability of degradation of nanotube
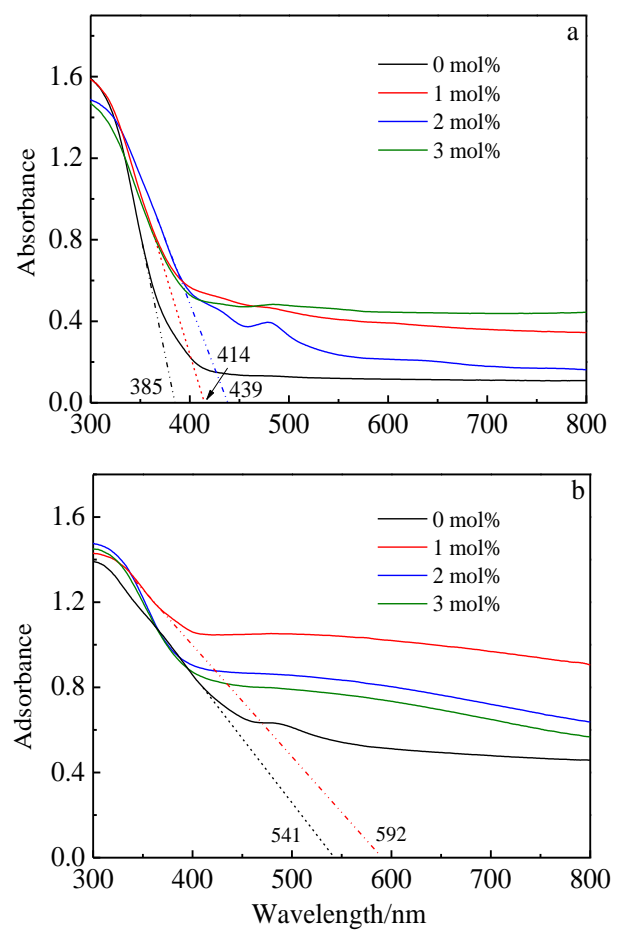

Fig.6 UV-vis curves of the Fe-doped nanotubes: (a) annealing in air and (b) reductive annealing 

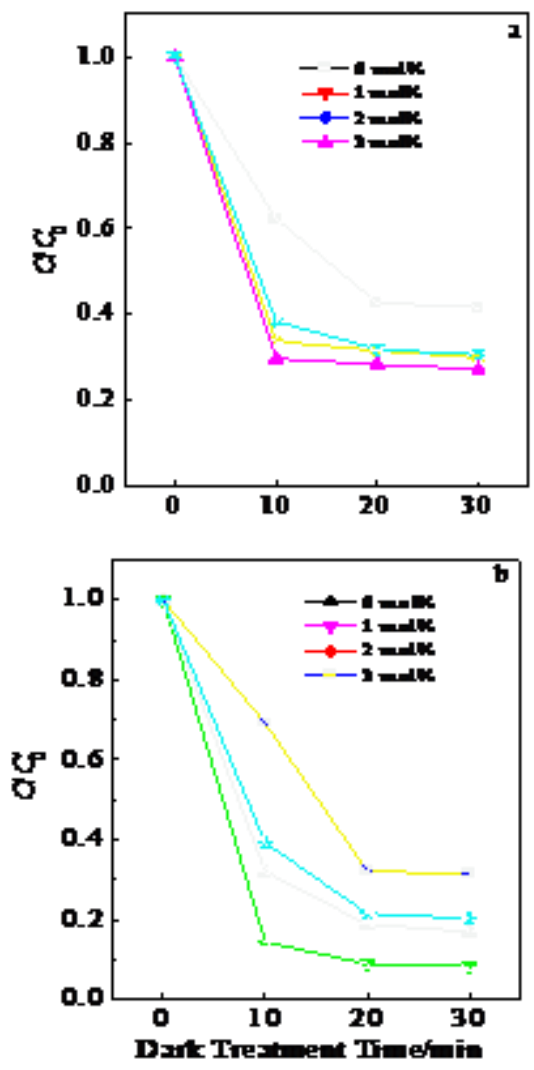

Fig.7 Variations of the MB concentrations in solutions: (a) annealing in air and (b) reductive annealing samples in recycle. Undoping and the annealing in air makes the degradation activity lose at first. $1 \mathrm{~mol} \%$ $\mathrm{Fe}$-doping and the reduction treatment produces the highest durability in degradation of the MB solution.

\section{Discussion}

The photocatalytic degradation of MB solution experiences two steps; first is the adsorption of $\mathrm{MB}$ on surface of the titania nanotubes; second is the oxidization-reduction reactions of $\mathrm{MB}$ on them under UV irradiation. As an excellent photocatalyst, it should possess high chemical activity, dispersity, specific surface area and the structural stability, which are greatly dependent on the microstructures of nanotubes that can be modified by ionic doping and preparation conditions such as the present Fe-doping and reductive pre-annealing.

\subsection{Adsorption and photocatalytic behaviors of titania crystals}

Titania generally has three states including an amorphous and two crystalline phases, anatase and rutile that are $n$-type semiconductors and have an orthogonal structure consisting of $\left[\mathrm{TiO}_{6}\right]$ octahedrons ${ }^{[43]}$. The nanostructured anatase are regarded as a highly-active photocatalyst when comparing with rutile and amorphous states ${ }^{[44]}$.

The titania crystals can adsorb organics such as MB molecules by means of physical and chemical routes. The physical adsorption is a result of attractions of the titania crystals to MB molecules through the so-called "Vanderwaals

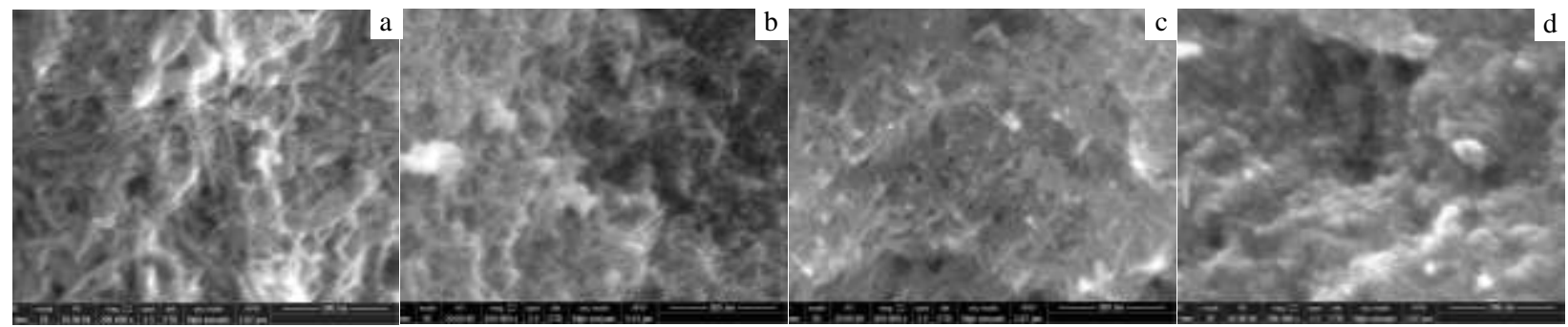

Fig.8 Surface morphologies of the nanotube samples after $30 \mathrm{~min}$ of dark treatment in MB solution: (a) undoping and annealing in air; (b) undoping and reductive annealing; (c) 1 mol\% Fe-doping and annealing in air; (d) 1 mol\% Fe-doping and reductive annealing

Forces"; in this case the surface area of titania crystals is an essential factor. The chemical adsorption is mainly associated with chemical bonds between titania and MB adsorptive because the surface of titania can be charged or formed covalent and coordination bonds with adsorptive ${ }^{[45,46]}$.

When irradiated by definite lights that have higher photon energy than forbidden band of titania, electrons are stimulated to conduction band and holes are created in valance band; thus, the photo-induced electrons and holes are generated and immigrate to surface of the crystals in an electronic field. The photo-induced holes have a strong oxidization ability due to their higher forbidden width $(3.2$ V), which can oxidize $\mathrm{OH}^{-}$and $\mathrm{H}_{2} \mathrm{O}$ that adsorb on surface of the titania into free radicals with much stronger oxidizability, such as $\cdot \mathrm{OH}, \mathrm{O}_{2} \cdot, \cdot \mathrm{HO}_{2}$ and $\cdot \mathrm{H}_{2} \mathrm{O}_{2}$. These radicals can oxidize the adsorbed organics such as $\mathrm{MB}$ into small molecules of $\mathrm{CO}_{2}$ and $\mathrm{H}_{2} \mathrm{O}$. Moreover, the holes can directly decompose the organic pollutants that do not absorb lights into $\mathrm{CO}_{2}$ and $\mathrm{H}_{2} \mathrm{O}$ by capturing the electrons (reduction) of the organics ${ }^{[15,37,47,48]}$. Therefore, the organic pollutants can be degraded by the photocatalytic reactions.

\subsection{Effect of Fe-doping and reduction treatment on microstructure, photochemical behaviors of the nanotubes}

Fe ions can be incorporated into titania lattice by their 

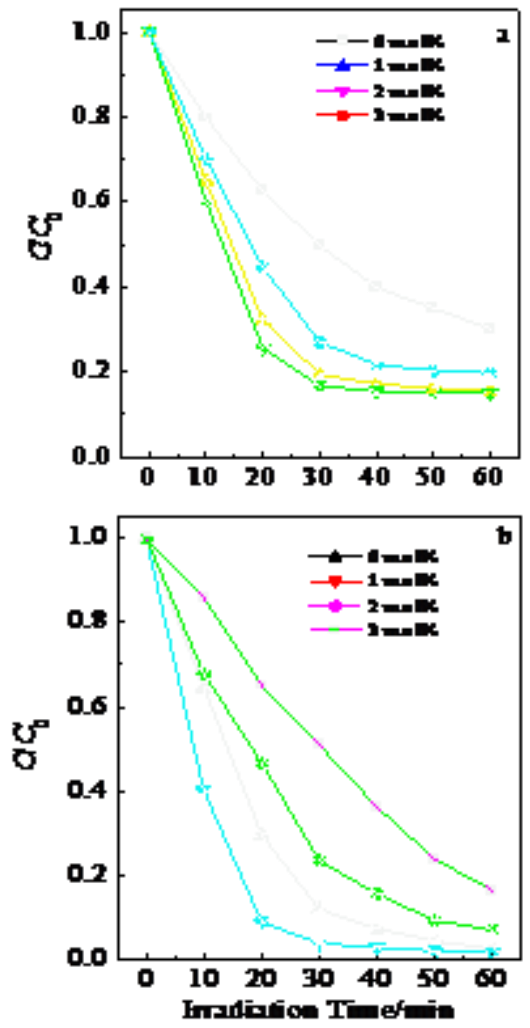

Fig.9 Methylene blue degradation curves of the Fe-doped titania nanotubes: (a) annealing in air and (b) reductive annealing

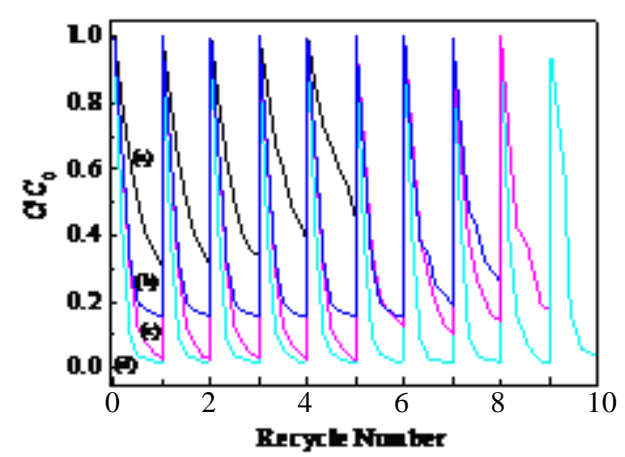

Fig.10 Durability of the nanotubes for degradation of $\mathrm{MB}$ solution: (a)undoping and annealing in air; (b) $2 \mathrm{~mol} \%$ Fe-doping and annealing in air; (c)undoping and reductive annealing; (d)1 mol\% Fe-doping and reductive annealing

substitutions for $\mathrm{Ti}^{4+}$ sites of $\left[\mathrm{TiO}_{6}\right]$ octahedrons, which simultaneously introduce oxygen vacancies $\left(\mathrm{V}_{\mathrm{O}}{ }^{2+}\right)$ to keep its electronic neutral. $\mathrm{Fe}^{3+}$ has two coordination states in the lattice, six $\mathrm{O}^{2+}$ ions and the five $\mathrm{O}^{2+}$ ions and one $\mathrm{V}_{\mathrm{O}}{ }^{2+}$. The $\mathrm{Fe}^{3+}$ ion can be a capture center for the hole because of its little stronger electronegativity than $\mathrm{Ti}^{4+}$; the $\mathrm{Fe}^{3+}$ ion with oxygen vacancy can be a capture center for electron because of its stronger attraction to electrons than $\mathrm{Ti}^{4+[47]}$. The capture centers make conduction band overlap with $d$ orbital of $\mathrm{Fe}^{3+}$ as the $\mathrm{Fe}^{3+}$ energy level is just below the conduction band and the $\mathrm{Fe}^{3+} / \mathrm{Fe}^{4+}$ energy level is slightly above the valence band of $\mathrm{TiO}_{2}{ }^{[14]}$. Thus, the $\mathrm{Fe}^{3+}$ doping narrows the band gap, extends the photoabsorption edge into visible-light range, separates the electrons and holes and restricts their recombination; however, extra doping in turn promotes their recombination and weakens the photocatalytic behaviors ${ }^{[13-19]}$.

The introduced oxygen vacancies also change the microstructure of anatase crystals. An oxygen vacancy $\mathrm{V}_{\mathrm{O}}{ }^{2+}$ produces an $F$ centre by trapping an electron pair, one of which tends to integrate with neighboring $\mathrm{Ti}^{4+}$ ion to generate $\mathrm{Ti}^{3+}$ and $F^{+}$centers; thus, the shallow and deep trapping states are formed. As the shallow-trapping states are built up below conduction band, the photoelectrons are easy to be excited to the conduction band of $\mathrm{TiO}_{2}{ }^{[48]}$. This mid-gap state creates a continuum of extending and overlapping with the conduction band edge instead of discrete donor states near the conduction band edge ${ }^{[25,26]}$. As the $\mathrm{TiO}_{2}$ has a higher dielectronic constant, these defects can stably exist in the crystals ${ }^{[47,49]}$ Thus, the oxygen vacancies trap photoelectrons, absorb light energy and produce more disorders in the lattice, which narrow the band gap, enhance visible light absorption and inhibit the combination of electron-hole pairs. In addition, the energy distribution of oxygen vacancies differs from that of a single defect in the crystals; these intrinsic defects unbalance strain and stress fields in the lattice and help to improve the hydrophilics and photocatalytic activity ${ }^{[49]}$.

A reduction treatment introduces low-valance $\mathrm{Fe}^{2+}$ and $\mathrm{Ti}^{3+}$ ions and more surface-adsorbed oxygen and oxygen vacancies (Table 2), which provide enough oxidization activity due to releasing of the lattice oxygen ${ }^{[50]}$. The surface-adsorbed oxygen and oxygen vacancies $\left(\mathrm{V}_{\mathrm{o}}{ }^{2+}\right)$ can attract the ions of $\mathrm{N}^{+}$and $\mathrm{Cl}^{-}$in $\mathrm{MB}$ chains (Fig.11), respectively, to form strong chemical adsorptions, which sufficiently stimulate the oxidization ability; thus, the photocatalytic degradation is greatly improved.<smiles>CN(C)c1ccc2nc3ccc(=[N+](C)C)cc-3sc2c1</smiles>

Fig.11 Molecular formula of methylene blue $\left(\mathrm{C}_{16} \mathrm{H}_{18} \mathrm{ClN}_{3} \mathrm{~S}_{2} \cdot 3 \mathrm{H}_{2} \mathrm{O}\right)$ 
Substitution of one $\mathrm{Fe}^{2+}$ ion for $\mathrm{Ti}^{4+}$ yields one oxygen vacancy $\left(\mathrm{V}_{\mathrm{O}}{ }^{2+}\right)$, which is more efficient than the substitution of $\mathrm{Fe}^{3+}$ for $\mathrm{Ti}^{4+}$ in creating oxygen vacancies. The $\mathrm{Fe}^{2+}$ ion has similar effects as $\mathrm{Fe}^{3+}$ does as it can transform into $\mathrm{Fe}^{3+}$ ion by releasing an electron or capturing a hole. Moreover, the combination of electron-hole pairs can be delayed and the stability of defects can be improved because $\mathrm{Fe}^{2+}$ ions make the titania lattice looser and the dielectronic constant increase. This indicates that the $\mathrm{Fe}^{2+}$ ions have additional effects on improvement of the photocatalytic behaviors.

Moreover, the Fe-doping and reduction treatment effectively change the physical characters of the one-dimensional nanotubes, such as good crystallinity of anatase, larger dispersity, specific surface area and the fast charge transfer rate between the surface of nanotubes and the electrolyte, which have positive effects on the photocatalytic degradation ${ }^{[5,19,20,44]}$. The degradation durability also ascribes to its adsorption and photocatalytic reactions, as well as the structure stability. As regard to the stability of the nanotubes containing oxygen vacancies and the low-valance ions, it can be explained in term of the thermodynamics ${ }^{[49]}$. The completely ordered arrangement of atoms represents the lowest energy state which is only stable at $0 \mathrm{~K}$. When $T>0 \mathrm{~K}$, the disorder will increase and the defects are introduced, which increase the energy of the crystal (defect-containing). On the other hand, the disorder makes the entropy increase simultaneously. However, the increase of entropy is gradually decreased with an increase of disorders, which result in a trend of first decreasing and then increase for total free energy of the defect-containing crystals. Therefore, the anatase crystals containing a small amount of the defects are quite stale ${ }^{[22,23,26]}$. In addition, the higher dielectronic constant of $\mathrm{TiO}_{2}$ crystals is another reason why the defects stably exist in the crystals as mentioned above.

\subsection{Coupling effect of the Fe-doping and reduction treatment on microstructure of titania crystals}

Under in the present conditions, $2 \mathrm{~mol} \%$ of Fe doping and the annealing in air produces better photocatalytic ability. In contrast, $1 \mathrm{~mol} \%$ of $\mathrm{Fe}$ doping and the reductive annealing produces the best photocatalytic ability; this may be produced by proper combination of the Fe amount and oxygen vacancy concentration. As more oxygen vacancies are introduced by a reductive annealing, the Fe content is reduced to $1 \mathrm{~mol} \%$. This may be due to that the oxygen vacancies strongly fasten photoelectrons, decrease their immigration speed and so increase their concentration in crystals; thus, a decrease in $\mathrm{Fe}$ dopants is required to increase their immigration speed by decreasing capture of $\mathrm{Fe}$ ions for the electrons.

From above reports on the Fe-doped titania nanostructures, it can be concluded that the suitable $\mathrm{Fe}$ dopant is about $0.5 \mathrm{~mol} \% \sim 1.5 \mathrm{~mol} \%$, which depends on the preparation methods, morphology and phase composition of titania structures and the sacrificial organics. At present, the optimum Fe content in nanotubes is $0.96 \mathrm{~mol} \%$ (nominal $1.0 \mathrm{~mol} \%$ ) in case of the reductive annealing, which just is the proper combination of $\mathrm{Fe}$ amount and the oxygen vacancy concentration.

\section{Conclusions}

1) The reductive pre-annealing yields more surfacechemisorbed oxygen by introducing lower valance $\mathrm{Fe}^{2+}$ and $\mathrm{Ti}^{3+}$ ions.

2) When compared with annealing in air, the reductive annealing greatly enhances specific surface area, MB adsorption ability and the photoabsorption threshold and flux of the nanotubes.

3) $1 \mathrm{~mol} \% \mathrm{Fe}$ doping and the reductive annealing yields the highest adsorption, photocatalytic efficiency and durability for degradation of MB solution.

4) $\mathrm{Fe}$ content of the nanotubes is decreased by $\mathrm{NaOH}$ immersion and $\mathrm{HCl}$ washing in the hydrothermal synthesis, especially in the case of pre-annealing in air.

\section{References}

1 Maheswari D, Venkatachalam P. Applied Solar Energy[J], 2013, 49(2): 93

2 Khan M A, Lee H, Yang Sr et al. AIChE Annual Meeting and Fall Showcase[C]. New York: American Institute of Chemical Engineers, 2005

3 Shikha Wadhwa, Jeremy W J Hamilton, Patrick S M Dunlop et al. Journal of Advanced Oxidation Technologies[J], 2011, 14(1): 1203

4 Qu J, Gao X P, Li G R et al. Journal of Physical Chemistry $C[\mathrm{~J}], 2009,113(8): 3359$

5 Du Jingjing, Wen Min, Chen Wen et al. IOP Conference Series Materials Science and Engineering[C]. Osaka: Ceramic Society of Japan, 2011

6 Hoffmann M R, Martin S T, Choi W Y et al. Chemical Reviews[J], 1995, 95(1): 69

7 Choi W, Termin A, Hoffmann M R. Angewandte Chemie [J], 1994, 106(10): 1148

8 Asahi R, Morikawa T, Ohwaki T et al. Science [J], 2001, 293(5528): 269

9 Khan S U M, Al-Shahry M, Ingler Jr W B. Science[J], 2002, 297(5590): 2243

$10 \mathrm{Hu}$ Xianchao, Wang Yanfei, Hu Sujuan et al. Journal of Zhejiang University[J], 2012, 46: 2121

11 Meng Fanchun, Jiang Fang, Zhou Yong et al. International Conference on Materials for Renewable Energy \& Environment [J], 2011, 2: 1213

12 Wang Yan, Jiang Zhaohua, Yang Fengjie. Materials Science \& Engineering $B[\mathrm{~J}], 2006,134(1): 76$

13 Yu Jiaguo, Xiang Quanjun, Zhou Minghua. Applied Catalysis $B[\mathrm{~J}], 2009,90(3-4): 595$ 
14 Li Jingxia, Xu Jianhua, Dai Weilin et al. Applied Catalysis $B$ Environmental[J], 2009, 85(3-4): 162

15 Vijayan P, Mahendiran C, Suresh C. Catalysis Today[J], 2009, 141(1-2): 220

16 Lin Xiaoxia, Rong Fei, Ji Xiang et al. Journal of Sol-Gel Science and Technology[J], 2011, 59(2): 283

17 Wang S, Lian J S, Zheng W $\mathrm{T}$ et al. Applied Surface Science [J], 2012, 263(263): 260

18 Wan Lin, Gao Yun, Xia Xiaohong et al. Materials Research Bulletin[J], 2011, 46(3): 442

19 Delekar S D, Yadav H M, Hankare P P. Current Nanoscience[J], 2013, 9(9): 235

20 Meng Fanchun, Jiang Fang, Zhou Yong et al. International Conference on Materials for Renewable Energy \& Environment [J], 2011, 2(8): 1213

21 Bouras P, Stathatos E, Lianos P et al. Applied Catalysis B Environmental[J], 2004, 51(4): 275

22 Zuo F, Wang L, Wu $\mathrm{T}$ et al. Journal of the American Chemical Society[J], 2010, 132(34): 11856

23 Gallo A, Montini T, Marelli M et al. Chemsuschem[J], 2012, 5(9): 1800

24 Sasikala R, Shirole A, Sudarsan V et al. International Journal of Hydrogen Energy[J], 2009, 34(9): 3621

25 Batakrushna Santara, Giri P K, Kenji Imakita et al. IOP Conference Series: Journal of Physics D[J], 2014, 47(21): 1

26 Chen X, Liu L, Yu P Y et al. Science[J], 2011, 331(6018): 746

27 Gharagozlou Mehrnaz, Bayati R. Materials Research Bulletin [J], 2015, 61: 340

28 Pan X Y, Ma X M. Journal of Solid State Chemistry[J], 2004, 177(11): 4098

29 Lin Fan, Jiang Dongmei, Lin Yan et al. Physica B[J], 2008, 403(13-16): 2193

30 Shi Zhiming, Wang Xiaohuan. Materials Chemistry \& Physics [J], 2012, 134(S2-3): 925

31 Teleki A, Pratsinis S E. Physical Chemistry Chemical Physics Pccp[J], 2009, 11(19): 3742

32 Komaguchi K, Maruoka $\mathrm{T}$, Nakano $\mathrm{H}$ et al. Journal of Physical Chemistry C[J], 2009, 114(2): 1240
33 Ta Na, Shi Zhiming, Chen Dandan et al. Rare Metal Materials \& Engineering [J], 2013, 42(11): 2212 (in Chinese)

34 Sharif Zein S H, Boccaccini A R. Industrial \& Engineering Chemistry Research[J], 2008, 47(17): 6598

35 Andersson S, Wadsley A D. Acta Crystallographica[J], 1962, 15(3): 194

36 Ou Hsinhung, Lo Shanglien. Separation \& Purification Technology[J], 2007, 58(1): 179

37 Qamar M, Yoon C R, Oh H J et al. Catalysis Today[J], 2007, 131(1): 3

38 Yu Yuxiang, Xu Dongsheng. Applied Catalysis B Environmental[J], 2007, 73: 166

39 Sabba D, Agarwala S, Pramana S S et al. Nanoscale Research Letters[J], 2014, 9(1): 1

40 Wang Baoxiang, Shi Yong, Xue Dongfeng. Journal of Solid State Chemistry[J], 2007, 180(3): 1028

41 Jiang H, Gao L. Materials Chemistry \& Physics[J], 2003, 77(3): 878

42 Xin B F, Ren Z Y, Wang P et al. Applied Surface Science[J], 2007, 253(9): 4390

43 Shi Z M, Yan L, Jin L N et al. Journal of Non-Crystalline Solids[J], 2007, 353(22-23): 2171

44 Ohtani B, Ogawa A Y, Nishimoto S I. Journal of Physical Chemistry B[J], 1997, 101(19): 3746

45 Ye Z H, Song Q. Adsorption and Ion Exchange, Chemical Engineering Handbook[M]. Beijing: Chemical Industry Press, 1985: 25 (in Chinese)

46 Kitagawa Hiroshi, Ichiro Suzuki. Basis and Design of Adsorption[M]. Tokyo: Uekiten, 1977: 47

47 Qian Y T. Crystallochemics[M]. Hefei: China Science and Technology University Press, 1998: 66

48 Santara Batakrushna, Giri $\mathrm{P}$ K, Imakita Kenji et al. Nanoscale[J], 2013, 5: 5476

49 Yu C F, Zhu X P. Introduction to Defect Chemistry[M]. Wuhan Wuhan Science and Engineering University Press, 2006: 32 (in Chinese)

50 Feng Xiuli, Wang Gongying, Qiu Fali. Progress in Chemistry [J], 2005, 17(6): 1019

\title{
预处理气氛对铁离子掺杂的氧化钛纳米管微结构和光催化活性的影响
}

\author{
史志铭，马 瑞，张曦予，汪丽娜，王小欢 \\ (内蒙古工业大学, 内蒙古 呼和浩特 010051)
}

\begin{abstract}
摘 要: 通过在空气和还原性气氛中煅烧铁离子掺杂的锐铁矿纳米粉体, 并且采用水热合成法制备了具有锐铁矿结构的纳米管, 研究 了它们的微结构和物理化学行为。研究发现, 与在空气中㷽烧相比, 还原性气氛下煅烧引入了低价态 $\mathrm{Fe}^{2+}$ 和 $\mathrm{Ti}^{3+}$ 离子以及更多的表面吸 附氧, 纳米管的比表面积、亚甲基蓝吸附能力以及光吸收阈值得到显著提高。1\% (摩尔分数) Fe 掺杂以及还原处理产生了最高的吸附 和光催化活性及其降解持久性, 过多掺杂反而降低了光催化性能。此外, 水热合成引起纳米管的含铁量下降。
\end{abstract} 关键词：氧化钛；纳米管；还原气氛烧结；掺杂；光催化；晶体缺陷

作者简介: 史志铭, 男, 1964 年生, 博士, 教授, 内蒙古工业大学材料科学与工程学院, 内蒙古 呼和浩特 010051, 电话: 0471-6575752, E-mail: shizm@imut.edu.cn 